\title{
Service Modularity in Managing Healthcare Logistics
}

\author{
Timo Pohjosenperä \\ Department of Marketing, Management and International Business, Oulu Business School, \\ University of Oulu, Oulu, Finland \\ Päivi Kekkonen \\ Industrial Engineering and Management, University of Oulu, Oulu, Finland, and \\ Saara Pekkarinen and Jari Juga \\ Department of Marketing, Management and International Business, Oulu Business School, \\ University of Oulu, Oulu, Finland
}

The International Journal of Logistics Management

Author's accepted manuscript

Pohjosenperä, T., Kekkonen, P., Pekkarinen, S., \& Juga, J. (2019). Service modularity in managing healthcare logistics. The International Journal of Logistics Management, 30(1), 174-194.

Permanent link to original publication

https://doi.org/10.1108/IJLM-12-2017-0338

\begin{abstract}
Purpose - The purpose of this paper is to examine how modularity is used for enabling value creation in managing healthcare logistics services.

Research design - Material logistics of four different kinds of hospitals is examined through a qualitative case study. The theoretical framework builds on the literature on healthcare logistics, service modularity and value creation.

Findings - The case hospitals have developed their material logistics independently from others when looking at the modularity of offerings, processes and organisations. Services, such as assortment management, shelving and developing an information platform, have been performed in-house partly by the care personnel, but steps towards modularised and standardised solutions are now being taken in the case hospitals, including ideas about outsourcing some of the services.

Research implications - This paper proposes seven modularity components for healthcare logistics management: segmentation, categorisation and unitisation of offerings, differentiation and decoupling of processes, and centralisation and specialisation of organisations. Thus, this study clarifies the threedimensional concept of modularity as a cognitive frame for managing logistics services with heterogeneous customer needs in a rapidly changing healthcare environment.

Practical implications - Modularity offers a tool for developing logistics services inside the hospital and increases possibilities to consider also external logistics service providers.

Social implications - Managing healthcare logistics services through modularity has potential social implications in developing healthcare processes and changing the usage of health services. On a wider scale, modularity is helping healthcare systems reaching their goals in terms of service quality and cost.

Originality - This paper shows the context-specific antecedents of service modularity and the usage of modular thinking in managing healthcare logistics.
\end{abstract}

Keywords: Service Modularity, Healthcare Logistics, Value Creation 


\section{Introduction}

The importance of material flows as part of health services is recognised nowadays both in the management of healthcare organisations and in academic research (e.g. Beier, 1995; Jarrett, 1998; Landry and Philippe, 2004; Kumar et al., 2008). This awareness originates from the global dilemma of healthcare organisations aiming to gain more value and reduce costs (see e.g. Kaplan and Porter, 2011). New models have been sought from industry for increasing healthcare logistics efficiency and effectiveness while still keeping in mind the unique features of healthcare that constrain the applicability of knowledge from the industrial and retail sectors (de Vries and Huijsman, 2011; Abdulsalam et al., 2015). Thus, healthcare logistics has become a constantly growing field of research and an important development area for healthcare organisations (Volland et al., 2017).

One of the concepts developed in the manufacturing industry is modularity, which is used as an enabler for postponement (e.g. Gualandris and Kalchschmidt, 2013) and masscustomisation (e.g. Feitzinger and Lee, 1997; Salvador et al., 2004) strategies. However, other disciplines have also adopted and modified the modularity concept (see e.g. Campagnolo and Camuffo, 2010). The expanding research stream of service modularity (Frandsen, 2017) has brought up new aspects from various empirical contexts (Brax et al., 2017), including logistics (Pekkarinen and Ulkuniemi, 2008; Bask et al., 2010) and recently also healthcare services (Vähätalo and Kallio, 2015; Silander et al., 2017). Overall, modularity can be seen as a useful cognitive frame for categorisation and interpretation of diverse economic phenomena (MacDuffie, 2013; Gärtner and Schön, 2015).

The aim of this study is to describe how modularity is used for enabling value creation in healthcare logistics services. We approach the question by first itemising the antecedents of modularity and then analysing the central components of modularity in healthcare logistics. Healthcare organisations, such as hospital units, wards and municipal health centres, have diverse needs for logistics services. As the needs are heterogeneous, modular services may offer a way to achieve the desired outcomes. In this examination, the outcomes of modularisation are reflected in the value creation literature, where the mechanisms, actors and their roles in value creation processes are under discussion. According to Grönroos and Voima (2013), the customer and service provider are in changing roles of both facilitating and creating value.

The empirical research is based on an interdisciplinary study carried out in four case hospitals in Finland. Two hospitals in northern Finland, a university hospital and a regional hospital, have their own in-house logistics service departments that take care of purchasing, deliveries, warehousing and service development activities. However, both hospitals are also considering opportunities for using external logistics service providers (LSPs) for some of their logistics operations. A regional hospital in south-western Finland has adopted a centralised model to also offer logistics services to municipal health centres in its region. Finally, a newly established private hospital in southern Finland has developed a modern, lean approach to material logistics and support services, including the systematic use of outsourced services from external providers.

This paper is organised as follows. Section 2 gives an overview of the concepts of modularity and value creation, especially in the context of healthcare material logistics. Section 3 introduces the case hospitals. Section 4 defines the qualitative methods and data collection of this research. The results and analysis in Sections 5 and 6 are organised in accordance with the supply chain partnering model by Lambert et al. (1996), describing the drivers, facilitators, components and outcomes of value creation through modularity. The results are discussed in Section 7, and the conclusions are presented in Section 8. 


\section{Modularity and value creation in healthcare logistics services}

\subsection{Modularity - definitions}

The history of modularity can be traced back to the standardisation efforts of the industrial era, for instance in operations management. Rutenberg (1971) addressed the need for commonality across product variants. Fundamental to modular designs are the modules that have a specific function; they should be relatively independent and have standardised interfaces to enable integration (Baldwin and Clark, 2000). Later, the concept of modularity has also been adopted in many other disciplines, including logistics services (e.g. Bask et al., 2010; Pekkarinen and Ulkuniemi, 2008) and healthcare (Vähätalo and Kallio, 2015; Broekhuis et al., 2017; Silander et al., 2017). In the service domain, modularity is defined as being formed of one or many bundles of tasks highly interdependent of each other but loosely dependent on other modules creating value for the customer through efficiency and customisation (see Kriegel et al., 2013; Ulkuniemi and Pekkarinen, 2011).

According to Pekkarinen and Ulkuniemi (2008), modular services may be recognised, developed and designed on the service, process and organisational levels. A service module can include one or more service elements offering a unique service characteristic for the customer. One example of modular service in healthcare is a surgery-specific kit (see Cardoen et al., 2015), which can significantly decrease the touchpoints needed to get medical materials ready for surgery. Process modules are standardised, indivisible process steps, while modular organisation is composed of internal functions and/or external partners. Examples of methods for increasing modularity in an organisation are outsourcing, contract manufacturing and forming alliances (Schilling and Steensma, 2001).

LSPs also use modularity in their service strategies and network management (Rajahonka et al., 2013). Modular structures are recognisable in logistics services such as warehousing, transportation, order picking, packaging, delivery, express carriers and value-added logistics centres, or any combination of these kinds of service modules. LSPs can specialise in these operations, offering the needed services as modules to several customers in supply chains and thereby reach scale economies. In most cases, using LSP modules means outsourcing for the customer organisations, which requires a certain consideration in the service interface compared to the development of in-house services (Bask et al., 2010.) Strategically, process modularisation enables new service development and a customer fit through new service extensions. The increase in complexity not only challenges traditional logistics service delivery systems, but it also requires new and more flexible resources by the LSP and the customers (Menor and Johnson, 2012).

In the healthcare service context, modularisation is affected by a variety of unique conditions. For instance, in the specialised healthcare setting, Silander et al. (2017) find that fragmented service delivery, professional autonomy, hierarchy, information asymmetry and the requirement to treat everyone either constrain or enable modularisation. Factors such as a clear division of work tasks and well-defined patient criteria have a favourable impact on the modularisation process.

Modularity may offer tools for identifying improvement opportunities in the care processes of healthcare institutions. Modular cure and care services may be divided into parts that can be further combined in several ways to address individual patient needs (Soffers et al., 2014). For example, de Blok et al. (2014) identified three steps of service package adaptation in elderly care: detecting changes in demand, reconfiguring packages and components, and aligning service providers. Typical interfaces during the three steps 
by which each organisation aimed to support elderly customers to live independently include continuous needs assessment, established communication lines and customer meetings.

Standardisation increases the efficiency of activities, their measurability and control opportunities (Sandoff, 2005). However, as standardisation of service components increases, so do the opportunities for customisation (Voss and Hsuan, 2009). Modular services provide flexibility and enable firms to serve various customer needs (Schilling and Steensma, 2001), and modularisation makes it possible to integrate and disintegrate potential new business components efficiently and effectively, either by sharing modular components internally or by outsourcing modular components to external suppliers (Janssen and Joha, 2008). Hence, offering customers more options in specifying features strongly affects the configuration of supply chains (Salvador et al., 2004).

\subsection{Value creation and co-creation in services}

Value is defined differently in different disciplines. In service marketing and management, one conceptualisation is the trade-off between benefits and sacrifices (e.g. Day, 1990). The means-ends model (Woodruff, 1997) explains the service provider's role in offering customers peace of mind. Later studies emphasise the perspective of seeing value in the context of customer experiences (e.g. Helkkula et al., 2012). Thus, the focus is no longer primarily on a customised bundle of products or services exchanged for a price, but value creation becomes an ongoing process that emphasises the customer's experiences and ability to extract value from products and other resources (Grönroos and Voima, 2013).

The value co-creation process calls for collaboration between the service provider and the customer (Macdonald et al., 2011). LSPs enable value creation for the business customer by supporting its core processes in a collaborative relationship or partnership (Lambert et al., 1998). This logistics value can be achieved through higher availability and timeliness (Fugate et al., 2010), which are service elements enabling the direct and indirect monetary as well as non-monetary value-in-use as perceived by the customer (Möller and Törrönen, 2003). In a modular approach, value co-creation potentially takes place in interfaces as: design interface between products and services, process interface between manufacturing and service-offering processes and information interfaces between information systems of the supplier and the customer. In these interfaces, the customer's role as a value co-creator is critical (Lin et al., 2015).

\subsection{Model for analysing value co-creation through modularity in healthcare logistics}

Relations between the antecedents, components and outcomes of value creation through modularity in healthcare logistics are organised in this study in accordance with the supply chain partnership model by Lambert et al. (1996). Thus, we propose that the model can also be applied for analysing other organisational forms such as contract manufacturing and alliances (see Helfat and Eisenhardt, 2004) and alternative work arrangements and alliances (see Schilling and Steensma, 2001). These loosely coupled organisation forms increase flexibility (Schilling and Steensma, 2001) and offer opportunities for efficient outsourcing arrangements when combined with modular product architectures (Mikkola, 2003). The proposed model (Figure 1) describes the drivers as motivations and benefits that the counterparts expect to get as they co-create value through modularity. Facilitators allow the co-creation of value to develop and grow stronger. The components are activities or managerial actions that are managed during the process, which in this study are related to the co-creation of value through modularity of offerings, processes and organisations. The model has potential outcomes beneficial to the stakeholders. 
To analyse the role of modularity as an instrument for value creation in healthcare logistics, supporting conceptual ingredients can be obtained from logistics and supply chain management research as well as in general modularity studies. First, supply chain segmentation strategies (Simchi-Levi, 2010; Godsell et al., 2011) open up avenues for greater efficiency and responsiveness based on demand profiling and market characteristics.

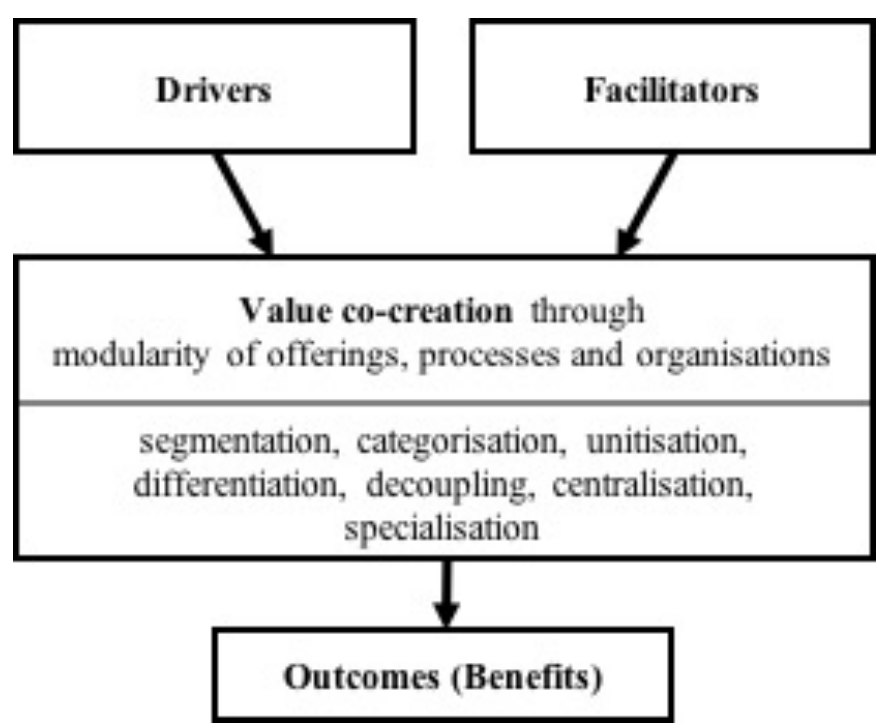

Figure 1. Antecedents and outcomes of value co-creation through service modularity.

In product modularity, variants targeted to different customer segments may change in one or several modules, and simultaneously the rest of the product may stay unaltered (see Salvador, 2007). Category management is seen as a collaborative initiative for implementing lean practices in retail supply chains (Piercy and Morgan, 1997) by grouping together interrelated products or services according to their functions (O'brien, 2015), while unitisation is associated with design-for-logistics strategies (Simchi-Levi et al., 2008). Differentiation in logistics refers to ways in which products, systems and processes can be categorised and separated to increase the effectiveness and efficiency of supply chains (Persson, 1995). Combined with standardised interfaces, process differentiation and decoupling enable the integration of independent parts of an organisation's offering (Baldwin and Clark, 2000; Rajahonka et al., 2013). This means separating the service structure into front and back office operations, for example (Metters and Vargas, 2000), or a decoupling of ordering from the delivery channel. In logistics services, this opens possibilities for centralising warehouses and thus specialising in certain parts of the decoupled processes (Bask et al., 2010).

\section{Case hospitals}

This empirical research comprises a description of healthcare logistics in four different kinds of hospitals in Finland: a university hospital, two regional hospitals and a new private hospital. All these cases have different approaches to healthcare material logistics in terms of services, processes and organisations. To simplify the research setting, the services in this study are limited to healthcare supplies, including clinical assortments such as bandages, single-use gloves, basic examination and surgical instruments such as needles and syringes. This leaves out support services such as pharmaceutics, food, 
laundry, waste disposal and assistive device service. The case hospitals are presented in Table 1 and in the following text.

Table 1. Main features and differences between the case hospitals and their logistical solutions.

\begin{tabular}{|l|l|l|l|l|}
\hline & $\begin{array}{l}\text { University } \\
\text { hospital }\end{array}$ & $\begin{array}{l}\text { Regional } \\
\text { Hospital A }\end{array}$ & $\begin{array}{l}\text { Regional } \\
\text { Hospital B }\end{array}$ & Private Hospital \\
\hline $\begin{array}{l}\text { Provided } \\
\text { treatments } \\
\text { speciality }\end{array}$ & $\begin{array}{l}\text { Most common } \\
\text { specialities }\end{array}$ & $\begin{array}{l}\text { Most common } \\
\text { specialities }\end{array}$ & $\begin{array}{l}\text { Orthopaedic day } \\
\text { surgeries and an } \\
\text { emergency unit. }\end{array}$ \\
\hline $\begin{array}{l}\text { Annual patient } \\
\text { visits }\end{array}$ & 580,000 & 200,000 & 425,000 & 40,000 \\
\hline $\begin{array}{l}\text { Logistics } \\
\text { organisation }\end{array}$ & $\begin{array}{l}\text { In-house logistics } \\
\text { unit }\end{array}$ & $\begin{array}{l}\text { In-house logistics } \\
\text { unit }\end{array}$ & $\begin{array}{l}\text { Joint logistics } \\
\text { centre with the } \\
\text { surrounding } \\
\text { municipalities }\end{array}$ & $\begin{array}{l}\text { Outsourced to } \\
\text { logistics service } \\
\text { providers }\end{array}$ \\
\hline $\begin{array}{l}\text { Purchasing } \\
\text { organisation }\end{array}$ & $\begin{array}{l}\text { In main response } \\
\text { of purchasing } \\
\text { nearly all } \\
\text { northern } \\
\text { Finland's public } \\
\text { healthcare items }\end{array}$ & $\begin{array}{l}\text { Uses University } \\
\text { Hospital's } \\
\text { tendered contracts }\end{array}$ & $\begin{array}{l}\text { Joint purchasing } \\
\text { centre with the } \\
\text { surrounding } \\
\text { municipalities }\end{array}$ & $\begin{array}{l}\text { 3 persons taking } \\
\text { care of the } \\
\text { hospital's } \\
\text { purchasing }\end{array}$ \\
\hline $\begin{array}{l}\text { Department } \\
\text { storage shelving } \\
\text { service }\end{array}$ & $\begin{array}{l}\text { In-house by } \\
\text { using partly } \\
\text { automated } \\
\text { closets }\end{array}$ & $\begin{array}{l}\text { In-house with } \\
\text { regular shelves. } \\
\text { Highly } \\
\text { standardised } \\
\text { planographs. }\end{array}$ & $\begin{array}{l}\text { Joint service for } \\
\text { the hospital and } \\
\text { the surrounding } \\
\text { primary health } \\
\text { centres. }\end{array}$ & $\begin{array}{l}\text { One storage } \\
\text { room. Shelving is } \\
\text { done by an } \\
\text { external service } \\
\text { provider. }\end{array}$ \\
\hline
\end{tabular}

The "university hospital" is located in northern Finland and represents one of the five university hospitals in the country. The hospital is in charge of providing specialised and demanding healthcare services for some 750,000 patients in its responsibility area covering more than half of the country's geographical area. The focus of this research is on the surgical ward, which represents the largest cost centre at the university hospital and consumes approximately one-third of the costs in the annual budget. On average, some 10,000 operations are conducted annually in this ward. The material flows are significant due to the complexity and number of operations conducted daily. An in-house logistics unit takes care of material operations at the university hospital. The surgery ward's nursing staff have reported occasional difficulties in meeting the logistics needs of the ward. The ward has had some unofficial discussions with external LSPs about the possibilities of using new logistics services for supporting the operations, but no concrete steps have been taken in this relationship.

In the university hospital's special responsibility area, there are four regional hospitals, including the Regional Hospital of Lapland (Regional Hospital A), which offers special health services to some 12,000 inhabitants. The research in this study focuses on the obstetrics and gynaecology ward and outpatient clinics for maternity and gynaecology patients. The ward employs about 60 nurses, midwifes and practical nurses working 24/7. Among its key responsibilities, the ward takes care of some 1,200 births a year. An inhouse logistics unit handles logistics and purchasing services in the hospital and between different facilities in the area. The unit also serves outside customers such as the health centres and military facilities in the area. The logistics unit offers a shelving service for the wards and outpatient clinics of the hospital, consisting of assortment management, ordering and shelving of the goods. During the case study, the service was used by the majority of wards and outpatient clinics and was also offered to outside customers, such 
as local health centres. In addition, the unit offers courier services and a delivery service for food, laundry and medicines and medical equipment for the wards.

As a comparison to the two public hospitals in northern Finland described above, this study also covers a regional hospital in southern Finland (Regional Hospital B). The hospital has adopted a centralised model in their material logistics by forming a joint logistics centre with the surrounding municipalities, which takes care of basic healthcare through the health centres. The logistics centre of the regional hospital takes care of assortment management, purchasing and other logistics support services of the hospital and the health centres. The logistics centre operates under the hospital district's service organisation, which also includes units for catering services, facility services, cleaning services and procurement. In the last years, the support services have undergone several reforms, which include building a new logistics centre and warehouse outside the hospital campus area to serve all the public healthcare units in the hospital district.

Another comparative case is a new "private hospital" owned by an insurance company in Finland. The hospital, founded in 2013, specialises in orthopaedic day surgeries and also operates an emergency unit. The hospital uses external LSPs for many activities that are performed in-house by the public hospitals. In addition, the remaining support activities are carried out by the nursing staff alongside their normal duties. Thus, the organisation for logistics and support activities is extremely lean and the processes streamlined. It should, however, be remembered that the hospital's services are limited to orthopaedics, and therefore the hospital cannot be fully compared to public hospitals that offer a broader array of healthcare services.

\section{$4 \quad$ Research methodology}

This research is a qualitative multiple case study with embedded units of analysis (Yin, 2013). A qualitative case approach is recommended when issues are complex and where alternating between the empirical field and different theoretical frameworks can be useful for generating additional insights (Orton, 1997; Yin, 2013). This study focuses on the contextualised logic of modularity and hence aims at theory elaboration (see Ketokivi and Choi, 2014). The units of analysis in this study are the modules in the open systems of healthcare organisations, but also people and their interaction, which is suitable in qualitative case research in the logistics discipline (see Gammelgaard, 2004; Aastrup and Halldorson, 2008).

The empirical data of the study is collected through various methods and multiple sources to add breadth and depth in understanding the phenomenon (Yin, 2013). First, background knowledge was obtained through a pre-study of the "university hospital" logistics (2012) and through discussions with the case hospitals and the LSP (20132014). Then the researchers worked closely in association with the case organisations in a multidisciplinary research project (2014-2016).

Data collection methods contain interviews and forms of group discussions. Focus groups are especially useful in identifying important qualifiers or contingencies that may be associated with an answer to a structured question. Furthermore, focus groups offer an opportunity for feedback from and response to the comments of others (Stewart and Shamdasani, 2014, p. 178.) The main steps in data collection are described in the following. Among pre-interviews, visits and a phone discussion, the primary data consists of nine semi-structured interviews and five focus groups (see Table 2). The primary data were recorded and transcribed to ensure the accuracy of the citations used. 


\begin{tabular}{|c|c|c|c|c|c|}
\hline No. & Organisation & Position(s) & Type & Date & Length \\
\hline 1 & $\begin{array}{l}\text { University } \\
\text { Hospital }\end{array}$ & $\begin{array}{l}\text { Staff Nurse and Nurse, } \\
\text { Anaesthesiology, } \\
\text { Surgery ward }\end{array}$ & $\begin{array}{c}\text { Semi-structured } \\
\text { interview }\end{array}$ & 8.1 .2015 & $1 \mathrm{~h} 7 \mathrm{~m}$ \\
\hline 2 & $\begin{array}{l}\text { University } \\
\text { Hospital }\end{array}$ & Procurement Manager & $\begin{array}{c}\text { Semi-structured } \\
\text { interview }\end{array}$ & 12.1 .2015 & 1h $3 \min$ \\
\hline 3 & $\begin{array}{l}\text { University } \\
\text { Hospital }\end{array}$ & $\begin{array}{c}\text { Staff Nurse, Surgery } \\
\text { ward }\end{array}$ & $\begin{array}{c}\text { Semi-structured } \\
\text { interview }\end{array}$ & 13.1 .2015 & $46 \mathrm{~min}$ \\
\hline 4 & $\begin{array}{l}\text { University } \\
\text { Hospital and } \\
\quad \text { LSP }\end{array}$ & $\begin{array}{c}\text { Staff Nurse, } \\
\text { Anaesthesiology Surgery } \\
\text { ward and Area Manager }\end{array}$ & Focus group & 4.2.2015 & 1h $58 \mathrm{~min}$ \\
\hline 5 & $\begin{array}{l}\text { University } \\
\text { Hospital }\end{array}$ & Head of Procurement & $\begin{array}{c}\text { Semi-structured } \\
\text { interview }\end{array}$ & 1.4 .2016 & $33 \mathrm{~min}$ \\
\hline 6 & LSP & Area Manager & $\begin{array}{l}\text { Semi-structured } \\
\text { interview }\end{array}$ & 13.4 .2016 & $56 \mathrm{~min}$ \\
\hline 7 & $\begin{array}{l}\text { Regional } \\
\text { Hospital A }\end{array}$ & Logistics Manager & $\begin{array}{l}\text { Semi-structured } \\
\text { interview }\end{array}$ & 23.3.2016 & 1h $32 \mathrm{~min}$ \\
\hline 8 & $\begin{array}{c}\text { Regional } \\
\text { Hospital B }\end{array}$ & $\begin{array}{l}\text { Head of logistics and } \\
\text { procurement }\end{array}$ & $\begin{array}{l}\text { Semi-structured } \\
\text { interview }\end{array}$ & 15.5 .2015 & $1 \mathrm{~h} 7 \mathrm{~min}$ \\
\hline 9 & $\begin{array}{c}\text { Regional } \\
\text { Hospital B }\end{array}$ & $\begin{array}{l}\text { Assist departmental } \\
\text { Manager }\end{array}$ & $\begin{array}{l}\text { Semi-structured } \\
\text { interview }\end{array}$ & 16.5 .2015 & $30 \mathrm{~min}$ \\
\hline 10 & $\begin{array}{l}\text { University } \\
\text { Hospital }\end{array}$ & $\begin{array}{l}\text { Transport Manager, } \\
\text { Warehouse Manager, } \\
\text { procurement Manager }\end{array}$ & Focus group & 5.5.2015 & $2 \mathrm{~h} 7 \mathrm{~m}$ \\
\hline 11 & $\begin{array}{l}\text { New Private } \\
\text { Hospital }\end{array}$ & $\begin{array}{l}\text { Nurse and IT service } \\
\text { provider }\end{array}$ & $\begin{array}{l}\text { Semi-structured } \\
\text { interview, visit }\end{array}$ & 13.2.2015 & $\begin{array}{r}2 \mathrm{~h} 30 \mathrm{~m} \\
\text { memo of } \\
16 \text { pages }\end{array}$ \\
\hline 12 & $\begin{array}{l}\text { IT service } \\
\text { provider }\end{array}$ & CEO & $\begin{array}{c}\text { Phone } \\
\text { discussion }\end{array}$ & 14.2.2017 & $12 \mathrm{~min}$ \\
\hline 13 & $\begin{array}{c}\text { Regional } \\
\text { Hospital A and } \\
\text { City } \\
\text { procurement }\end{array}$ & $\begin{array}{l}\text { Development Manager, } \\
\text { Procurement expert }\end{array}$ & Focus group & 27.5.2015 & $17 \mathrm{~min}$ \\
\hline 14 & $\begin{array}{l}\text { University } \\
\text { Hospital, } \\
\text { Consulting } \\
\text { company }\end{array}$ & $\begin{array}{l}\text { Procurement Manager, } \\
\text { CEO }\end{array}$ & Focus group & 27.5.2015 & $23 \mathrm{~min}$ \\
\hline 15 & $\begin{array}{l}\text { University } \\
\text { Hospital } \\
\text { Regional } \\
\text { Hospital A, } \\
\text { LSP, IT } \\
\text { service } \\
\text { provider. }\end{array}$ & $\begin{array}{l}\text { Procurement Manager, } \\
\text { Warehouse Manager, } \\
\text { Logistics Manager, } \\
\text { Development Manager, } \\
\text { Area Manager, CEO }\end{array}$ & $\begin{array}{l}\text { Seminar Group } \\
\text { Discussions }\end{array}$ & 18.2.2016 & $2 \mathrm{~h} 51 \mathrm{~m}$ \\
\hline
\end{tabular}

In 2015, researchers conducted interviews and visits to university hospital purchasing organisation and surgery ward personnel (Nos 1-3 in Table 2) to identify both organisations and challenges in material logistics. These challenges were introduced in a focus group discussion (4) to find new solutions with a representative of an LSP. Later, service modularity in the organisations was particularly clarified in the interviews ( 5 and 6) in 2016 with the hospital's purchasing manager and LSP representative.

In 2015, one of the researchers observed nursing staff and logistics personnel in obstetric ward of the Regional Hospital A. The recognised challenges were later in 2015 discussed in joint focus group discussions with the both working groups. Later in 2016, 
other researchers arranged an interview (7) with logistics manager to clarify the latest developments of the hospital's material logistics arrangements.

Interviews in Regional Hospital B were arranged in 2015, first with the centralised logistics organisation's manager in the logistics centre (8) and then with the municipal health centre's customer organisation representative (9). This gave researchers information about the centralised model from two different viewpoints, which were further compared to the university hospital's operations in a group discussion (10).

A visit (11) to the private hospital was arranged in 2015. The nurse who has had a central role in developing material logistics in the hospital presented the hospital for the researchers. The CEO of an information technology provider that has been designing and implementing the material information and communication technology (ICT) system in the hospital attended the visit. Researchers formed a 16-page report of the visit describing the material logistics processes in the hospital. The report was commented on by the nurse and the CEO. The role of the ICT system in the processes was clarified later in 2016 in a phone discussion (12) with the CEO.

The initial results of the cases were reported and presented for groups of experts, including members from the hospitals in 2015 in focus group discussions (13 and 14). Later in 2016, the end seminar (15) of the research project gave the 45 attendees the possibility to comment on the results. In these documented discussions, the results were both assured and refined to meet the features of a novel context in healthcare.

\section{Antecedents for modularity in healthcare logistics}

As suggested in the partnership model by Lambert et al. (1996), there are various antecedents that drive and facilitate changes in supply chains. In this section, some of the key drivers and facilitators underlying the changes in healthcare logistics will be examined.

\subsection{Drivers}

Healthcare organisations are facing big challenges, as cost reductions are needed and service improvements are expected. In Finland, the healthcare expenditure as a percentage of gross domestic product has risen from 6.9 per cent in 2000 to 9.4 per cent in 2015. This is still slightly below the EU average, but the growth rate in Finland has been higher than in the rest of the EU. One of the main challenges comes from the ageing population, which is especially problematic in peripheral regions. This will increase the demand for healthcare services of all kinds: care and cure, at home and at institutions.

To combat the growing costs, the Finnish Government introduced a healthcare reform to be implemented by the year 2019. In short, the government aims to create larger regional units for the provision of social and healthcare services so that some examinations, procedures and treatments are centralised at the national and regional levels. In addition, the reform aims at simplifying the healthcare funding system and increasing the client's freedom to choose the provider of primary healthcare service. Besides cost reductions, the reform aims at improved service quality and flexibility.

The improvement efforts in healthcare have mainly focused on core processes, that is, patient care and cure, while less attention has been given to support activities and logistics. In recent years, however, the interest in these supporting functions has increased, as best practice examples and benchmarks from industry and retail branches have shown that there also may be considerable potential for improvements in healthcare logistics and supply chain management. In addition, the growing role of private healthcare 
providers have made public organisations look more critically into their operations, not only in care and cure, but also in areas such as logistics and other support operations.

Especially in the northern and eastern parts of Finland, long distances and a decreasing population put an extra challenge to the healthcare system. Therefore, new logistics solutions have been sought to increase the efficiency of patient care and material flow management. For instance, mobile services have been introduced to replace expensive institutionalised care and inventory centralisation with continuous replenishment processes implemented to streamline logistics. Also, the idea of modularity has come up as a possible way to improve operations both within and between organisations:

I see that there is growing potential for modularity, ... many kinds of activities from laundry to food supply and cleaning, pharmacy, instrument maintenance and care material supply. There is, for sure, potential that they don't all need to be hospital's own functions. That kinds of services, for instance food supply and cleaning, that are in other markets as well, that is their core business. In hospital, these support services are indeed support services, not eventually core business for hospital, certainly essential part of the entity. Modularity could be utilised and there is plausibly potential. (University hospital, Head of Procurement).

Although modularity is still an abstract concept in service settings such as healthcare, its potential is recognised for systematising the diversity of practices and processes in support activities within and between organisations. Especially in the public healthcare sector, where the organisations are complex and demands are heterogeneous, modularity can serve as a cognitive frame for organising ideas and seeking improvement opportunities. Elements and interfaces increase the clarity, connectivity and measurability of support activities and thereby support the broader goals of healthcare efficiency and effectiveness.

\subsection{Facilitators}

Besides factors driving for modularity, there are enablers and facilitators that help making modularity happen in the service business environment. These are partly paralleled with physical product modularity but when it comes to service modularity, it is also important to recognise "softer" facilitators, especially during the development stage of modular service models and processes.

Support processes such as logistics should serve as an instrument for increasing healthcare effectiveness with the customer as the focal point. Also, external LSPs understand that effectiveness is not restricted to the immediate relationship between the LSP and the healthcare organisation, but everyone should have their eyes on the end customer - the patient:

When I think about healthcare effectiveness, the logistics processes should be conducted separately so that focus can be directed on patient care... New ideas for achieving this can be born if healthcare personnel and logistics professionals meet to share their views - we need cooperation. (LSP's representative).

The LSP sees its own processes largely through the lenses of modularity - this applies to haulage, warehousing and replenishment services that can be designed to match various needs and to shelving services that are offered as a value-added service option. In public healthcare, support processes have traditionally been conducted internally, and mutual understanding about the structuring of the processes is still quite vague. However, the university hospital sees possibilities for increasing LSP participation, especially when the extension of support services to different regional units comes into question. Service innovations, when established at one location, can also be readily experimented with on a wider scale on a collaborative basis if needed. 
Two central aspects related to the interfaces in modular systems were pinpointed by the interviewees: ICT and standardisation. The former is a challenge especially in public healthcare organisations that have built their ICT infrastructure over a long period and with significantly different demands than exist in today's digital service environment. Sometimes this has slowed down the adoption of new logistics models, as changes have been required in information systems. The situation looks quite different for the private hospital. They have acquired a logistics solution on a software-as-a-service basis. As an off-the-shelf solution, the system is easily scalable, and the implementation time is fairly short. However, the hospital has a relatively limited range of operations and items, which makes it easier to use a standard software solution for its logistics needs.

Standardisation is also a critical enabler of modularity in healthcare support operations. This applies to all aspects of logistics operations - selection of items, replenishment processes and information management both inside the organisations and between them. Standardisation can be an arduous task and not without resistance, but in most cases the work pays off. As mentioned by the materials manager of the regional hospital, there are always some people whose work will be affected when reforms are made, but eventually the improvements in the system as a whole will prevail and the feedback is mostly positive if things get done in a rational way.

\section{Modularity in material logistics of the case hospitals}

This section analyses the manifestations of modularity in the material logistics activities of the case hospitals. The analysis consists of the model of modularity with three dimensions: offerings, processes and organisations (see Pekkarinen and Ulkuniemi, 2008). The dimensions are further divided into more specific components that were tentatively identified in Section 2.3. Value co-creation among parties is illustrated through events and examples for each dimension.

\subsection{Modular offerings}

Modular products and services - or modular offerings - form the basis upon which healthcare organisations can start developing their material logistics concepts. The interview data raise modular offerings that are created and managed through segmentation, categorisation and unitisation.

Segmentation. From a material logistics point of view, different healthcare units can be segmented by their logistics needs, for instance the variety of items, level of inventory, replenishment frequency and the preparation requirements for products and instruments. Most of the case hospitals offer a fairly wide range of healthcare operations that entail varying needs for the supporting logistics. Some operations, like elective surgeries, can be planned beforehand and could therefore use ERP systems to order all the needed materials and logistics services based on the schedules of the operations. However, the hospitals also need to be prepared for unplanned operations that pose different needs for the offerings:

In our hospital, 53\% are emergency operations and $47 \%$ are elective that we know about beforehand, and we can therefore optimise delivery time and when the materials need to be in place. Emergency operations have some implications [for material logistics], and therefore we need to continue having a bit oversized inventories. (Regional Hospital A, Development Manager)

The most varied customer segments, and therefore also logistics needs, can be found at the university hospital that offers a very large variety of medical operations. Customer units such as the surgery ward and the obstetrics and gynaecology ward should be 
considered different customer segments with different logistics needs. As a contrasting example, the private hospital has a considerably smaller variety of patient operations. Thus, from a material logistics standpoint, the entire hospital can be seen as belonging to a single segment. Furthermore, the municipal health centres are in many ways a different customer segment:

Health centres form their own group [compared to hospitals]. They have much more limited assortment and they work mostly in a similar way everywhere. (University Hospital, Purchasing Manager)

In some health centres there are inpatient wards, and in others not... In the well-being centres, there is usually only a nurse or doctor's reception, where the patients don't stay for long. The amount of materials is then so much smaller that the delivery frequency could be less than once a week. (University Hospital, Transport Manager)

Compared to each other, the hospitals and care units might have even more variation in their logistics needs if the hospitals begin to specialise in some specific care operations in the future. This will increase the need for logistics providers, internal or external, to think of the segmentation opportunities in their service offerings.

Categorisation. There is considerable variety in the assortment management methods in the case hospitals to standardise and categorise the offering. In the hospitals, the nurses and doctors have traditionally had plenty of options for different care items. This serves the individual needs of the care personnel, but causes inefficiency in tendering, ordering and placement processes. To a large extent, the variety is explained by the heterogeneous needs of the departments and wards, but also by personal habits, insufficient coordination and the lack of information. However, things are changing and the hospitals see opportunities and benefits related to standardisation by categorising their assortments.

The healthcare organisations plan material assortments to create best value at minimum system-level costs. Indeed, all case hospitals see assortment management as a fundamental part of developing their operations:

The earlier situation was such that a huge workload was used for tendering to get results, and still everyone used the products as they wanted to. It is first of all a matter of cost ... prices are different, and the price of logistics that comes when there's everything for everyone based on individual preferences, not the actual needs.... But then when the assortment is standardised, it is adequate also for care personnel, ... there's no need for a broad repertoire in use. I strongly think that it helps life in the care units as well. It is cheaper for customers ... the money can be used for something else, hopefully for the core work in the units. (Regional Hospital B, Logistics Manager)

With a number of suppliers for healthcare-related supplies and services, it is normally easy to get competitive offerings, but the challenge is to organise assortments in a way that gives an efficient match between supply-demand characteristics and logistics processes. Typically, this requires some basis for classifying the assortment; it can be demand volume or regularity, supply lead time and uncertainty, or the like. However, it is also essential that the information platform supports modular assortment management. For instance, it should be possible to choose items or product groups for competitive tendering, and the resulting changes to product and supplier data should be easy to implement. As the software provider explains:

The assortment in the system can be defined item by item or on a group level. Updated assortment data can be imported with spreadsheets, and there is a functionality that does certain checks automatically so that assortment changes can be carried out swiftly. (Software Provider, CEO) 
Unitisation. Managing a modular offering is also done by unitizing the assortments. At the most basic level, this can mean material kits that have been developed for surgery and other hospital operations. At the university hospital, for instance, the hospital's internal service unit collects items for specific surgery operations and packs them into boxes that are delivered to operating rooms before surgery. These kits are very modular and allow the picking and packing of items to be performed at suitable times and outside the operation rooms:

We are doing surgery-specific kits ... our shelving service collects instruments, medical supplies and some pharmacy items that we have the right to handle. We need to consider Fimea [medical administration] regulations and other interfaces. Now we are extending this service and it's getting good feedback. (University hospital, Warehouse Manager)

Another form of modular unitisation, especially for consumable items, textiles, etc., can be accomplished by standardisation of storage spaces such as shelves, planograms, cabinets and cupboards. If these are standardised for similar items in different wards and departments, the assortments can be controlled more efficiently and replenishment operations are simplified. An example is offered by Regional Hospital A in northern Finland. Its material services unit replenishes over 40 storage points inside the hospital and more than 300 outside the hospital - the most distant ones several hundred kilometres from the hospital. In recent years, a healthcare logistician has been working almost full time in developing the assortments and replenishment models for the customer wards and departments. Shelf locations, planograms and layouts have been one of the central planning objects:

At both ends of the corridor, there are practically identical storage points, as in many other patient wards. The storage is arranged in a way that the nurse finds the product because it's in the same place ... the logic is always the same. And it is easy for the person checking the stock levels and doing replenishments. With some experience, it is easy to see what is on the shelf and what is needed. (Regional Hospital A, Logistics Manager)

Modular offerings consist of product and service assortments that increase the efficiency of healthcare operations without compromising availability and reliability requirements. At the present moment, the basic forms of modular offerings such as material kits or standardised planograms, shelf and storage layouts are widely utilised, but more systematic utilisation of modular assortments is still quite limited. Besides adequate information platforms, modular assortments also require processes and organisations that support the offerings. Once established, however, the modular offerings can be easily extended geographically. In addition, the modular offerings also increase flexibility in the use of external providers for logistics and material supply services.

\subsection{Modular processes}

Modular product and service offerings are supported with suitable process architectures. This means that processes too are modularised - that is, they are standardised and differentiated into sub-processes that lend themselves for decoupling and resequencing to meet varying needs and scalable to meet parallel needs efficiently. Modular processes can be achieved through process differentiation and decoupling. The former means that different processes are employed to accommodate different categories of items and assortments, while the latter means that support processes are separated from patient care processes. Well-aligned product assortments and process architectures offer cost benefits and service advantages, as personnel can focus on their own areas of specialisation.

Differentiation. At Regional Hospital B, warehousing was recently centralised to a logistics centre that now serves most of the healthcare units in its region. Before the 
reform, the healthcare units had their own warehouses, and many people were involved in procurement and ordering processes. In the centralised model, the assortments for basic items were redefined and ordering and delivery processes were standardised. The ABC classification is used as the basis for defining delivery processes: routine items are included in the shelving service where the service unit is responsible for keeping up predefined stock levels at the storage points. Alternatively, based on the price of items, the reorder-level method can be used for replenishments. For the most expensive items, direct deliveries are used based on individual orders. The delivery frequencies vary based on demand and the criticality of the items. The big hospitals can be served twice a day if needed. A lot of effort has been given to defining appropriate delivery models and frequencies for different item categories and user locations:

We are also trying to avoid over-service... We try to develop rational service models for customers by balancing picking and delivery processes ... so that our customers know when they will get the products and that delivery planning is based on adequate expertise. (Regional Hospital B, Logistics Manager)

Decoupling. The separation (decoupling) of patient processes from support processes is one important method for improving the efficiency and quality of healthcare operations. Routine replenishments to the wards and storage points in the vicinity of operating rooms can be done by logistics service personnel with the help of the shelving service concept. Disturbances to patient processes can be diminished by designing layouts and storage points from a modularity point of view. In one case hospital, cupboard doors were removed so that picking and replenishments can be done more quickly and the material situation becomes more visible. In another, cabinets in the operating rooms are on wheels so they can be moved in and out for replenishment to eliminate unnecessary waiting times between operations. The biggest advantage, however, is the time savings for the nursing staff, which can be used for patient work instead of material replenishments:

Earlier the nurses had to do the orders, which took a lot of time. Now all the supplies come to the shelf. We don't have to worry about it. This is good. (Regional Hospital B, Assistant Department Manager).

In healthcare, it is important that at least some of the support processes can be decoupled from the actual care processes such as complex surgical operations so that the lead times of operations can be shortened. The decoupling of material processes from support processes is different in regional hospitals compared to a university hospital where both processes are both diverse and complex.

\subsection{Modular organisation}

Organisational modularity has been seen as a strategy through which organisations utilise autonomous but interrelated subsystems for managing complex entities. Instead of controlling complex details, the organisation coordinates fewer subsystems and interfaces and thus streamlines the organisation or network of organisations. In the service operations context, organisational modularity is associated with modular processes, as process decoupling increases the opportunities for interface simplification and functional specialisation.

Centralisation. There has been a tendency in public healthcare organisations to centralise the management of materials and logistics activities during the last decades. The biggest units have taken much of the responsibility for purchasing and procurement activities that are subjected to public procurement legislation. For instance, the university hospital acquires most of the materials for the hospitals and healthcare units in its own 
hospital district as well as some items for the wider special responsibility area covering all of northern Finland. However, the role of the purchasing organisation varies based on the needs in different procurement categories:

[At the university hospital district] we procure services, equipment and materials. They have their own processes. The operative unit is the decision-maker in the acquisitions of services and equipment, but we arrange the process. ... For materials and supplies we have the decision-making responsibility. (University Hospital, Procurement Manager).

By consolidating procurement, both volume advantages and operational efficiencies can be accomplished. The same benefits are achieved by centralising warehousing activities and organising replenishments by specialist personnel. However, while centralisation does not automatically involve modularity, it is easy to see that specialisation increases coherence and makes the operations and processes replicable to multiple customer units:

This is now a genuinely specialist organisation... We can duplicate and produce coherent service, regardless of who is the customer. ... When the service is taken into use, it is carefully conceptualised - there is a big advantage when it is done, and conceptualised, it is always done the same way and it is done coherently. (Regional Hospital B, Logistics Manager)

Specialisation. With the specialisation of tasks and roles, the question arises about the interfaces between the functions and units in organisations. Previously, the nursing staff were involved in the support logistics processes, and they were also normally better informed about the events and changes related to the materials. Now, in those hospitals and wards where the support personnel take care of ordering and replenishment activities, the nurses have sometimes lost time on searching for items that have been replaced, and the information about changes has not reached the care personnel. To improve communication, information systems provide one part of the answer. However, simple visual tools also help communication between the material support and nursing personnel. In the present project, for instance, a simple alert sign was suggested in one of the joint workshops to notify nursing staff of item changes at the storage points.

Development of organisational interfaces, especially communication, needs continuous attention by the personnel of the wards and support organisations. The case hospitals have established various cooperative forums for discussing issues and enhancing communication between the medical and support personnel. These range from regular meetings of work groups to ad hoc workshops and informal discussions. For instance, Regional Hospital B describes the decision making related to assortment management:

For every tendered product group, we have a specialist team working in the tendering process. There are medical experts, nurses, etc. That's where the process starts. It must be mentioned, however, that this is not without problems. The idea is that we can take into account the opinions of the experts, but there are big challenges. People don't understand their roles... We do not get enough feedback during the process, and especially in special healthcare items there is a lot of discussion after the procurement decision regarding different needs. (Regional Hospital B, Logistics Manager). 


\section{Discussion}

\subsection{Modularity as a component in healthcare logistics value creation}

The three dimensions of modularity (Pekkarinen and Ulkuniemi, 2008) in healthcare logistics are summarised in Table 3. Each dimension is divided into more specific components (segmentation, categorisation and unitisation of offerings, differentiation and decoupling of processes, and centralisation and specialisation of organisations) that were tentatively identified in Section 2.3, and then authenticated and classified on the basis of the empirical interview data. The table also presents examples from the case hospitals that illustrate how modularity manifests itself in healthcare services: they serve a specific function, they are relatively independent and they have standardised interfaces to enable integration and are relatively independent parts of an organisation's offering. 


\section{Table 3, Classification of value creation through modularity in healthcare logistics}

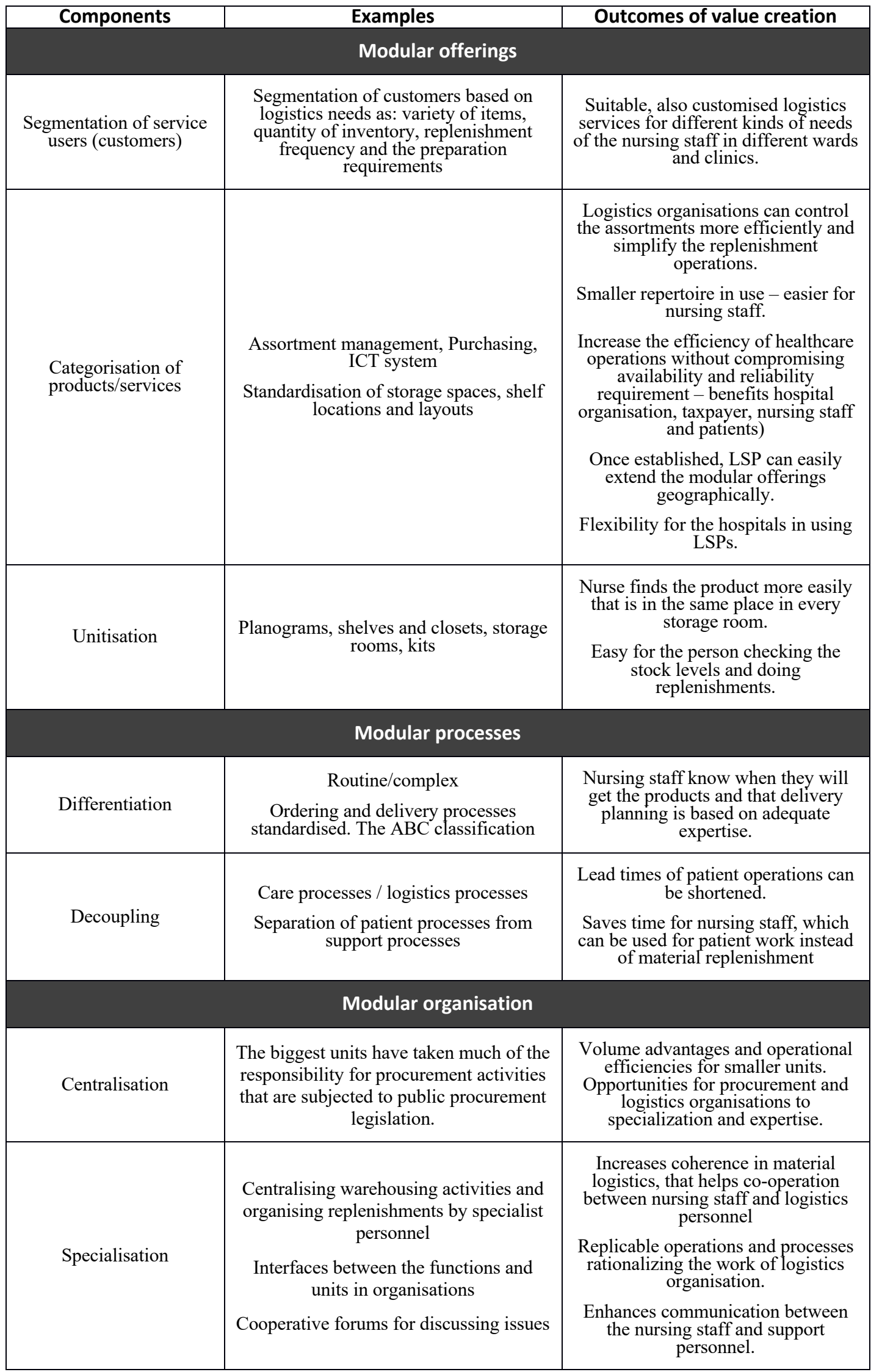




\subsection{Beneficial outcomes through modularity}

The empirical analysis supports the view that the users of a service create value by, and for, themselves (Grönroos and Voima, 2013). The support service does not create value directly but facilitates value creation of the users. In the healthcare context, the nursing staff are in a critical role at the interface (see Lin et al., 2015) between the patients and the support services. They rely on logistics processes for a fluent and efficient care of the patients. The well-being of the nursing staff in their work can be promoted through efficient and reliable support processes that can help them concentrate on actual nursing work. This is where modularity can bring indirect, non-monetary value (Möller and Törrönen, 2003) through peace of mind and more time for nursing staff with the patients.

Logistics creates value by securing the availability of materials at the right time, the right place, the right cost and the right quality (see Fugate et al., 2010; Lambert et al., 1998). The empirical analysis of this study shows that assortment planning and standardised layouts of storage and shelf space help nurses in finding the materials and the support staff in providing timely replenishments. A well-organised logistics service saves the nursing staff's time for actual patient work instead of material replenishment and other support activities. Developing modular offerings requires time and resources, but once conceptualised, the service can be easily extended to new customer units and geographical locations. The modular offerings also increase flexibility in the use of external providers for logistics and material supply services.

To sum up, modular logistics services in healthcare can bring well-being for employees, operational efficiencies, volume advantages and coherence, which makes the operations and processes replicable to multiple customer units. Effectiveness increases without compromising availability and reliability requirements. Also, the lead times of patient processes can be shortened, which contributes to the overall cost and operational efficiency of the healthcare system. This increases the potential for visible monetary benefits that can be perceived by the strategic level actors in healthcare organisations

Logistics creates value by securing the availability of materials at the right time, the right place, the right cost and the right quality (see Fugate et al., 2010; Lambert et al., 1998). The empirical analysis of this study shows that assortment planning and standardised layouts of storage and shelf space help nurses in finding the materials and the support staff in providing timely replenishments. A well-organised logistics service saves the nursing staff's time for actual patient work instead of material replenishment and other support activities. Developing modular offerings requires time and resources, but once conceptualised, the service can be easily extended to new customer units and geographical locations. The modular offerings also increase flexibility in the use of external providers for logistics and material supply services.

To sum up, modular logistics services in healthcare can bring well-being for employees, operational efficiencies, volume advantages and coherence, which makes the operations and processes replicable to multiple customer units. Effectiveness increases without compromising availability and reliability requirements. Also, the lead times of patient processes can be shortened, which contributes to the overall cost and operational efficiency of the healthcare system. This increases the potential for visible monetary benefits that can be perceived by the strategic level actors in healthcare organisations.

\section{Conclusions}

This paper connects discussions of healthcare logistics services, modularity and value creation. The drivers and facilitators of modularity in healthcare logistics are described as well as the possible outcomes of modularisation. The case study of four hospitals 
indicates similarities and differences in material logistics arrangements regarding the modularity of offerings, processes and organisations. Many support services, such as assortment management, shelving and the information platform, have traditionally been performed in-house and partly by the care personnel, but steps towards modularised and standardised solutions are now being taken, including ideas about outsourcing some of the services. The interviewees see similarities here with present-day retail logistics management, such as category management and efficient consumer response. Modularity can serve to create efficient assortments and replenishment models that support the planning and control of material flows and inventories.

Based on the empirical findings and the theoretical background, this paper proposes seven modularity components for healthcare logistics management: segmentation, categorisation and unitisation of offerings, differentiation and decoupling of processes, and centralisation and specialisation of organisations. These components are generally recognised in the logistics and supply chain management literature and have also been addressed in general modularity research. All these components have potentially positive impacts on reliability and security, and may thus result in less stress for the nursing staff who work in a key role at the interface of support processes and actual patient processes. Consequently, care personnel have more time for patient work that directly affects core health operations. When it comes to the economic value of the support operations, modularity increases replicability, scalability and coherence, which all increase the operational efficiency of healthcare organisations. The findings and the discussion of the previous literature is concluded in Figure 2.

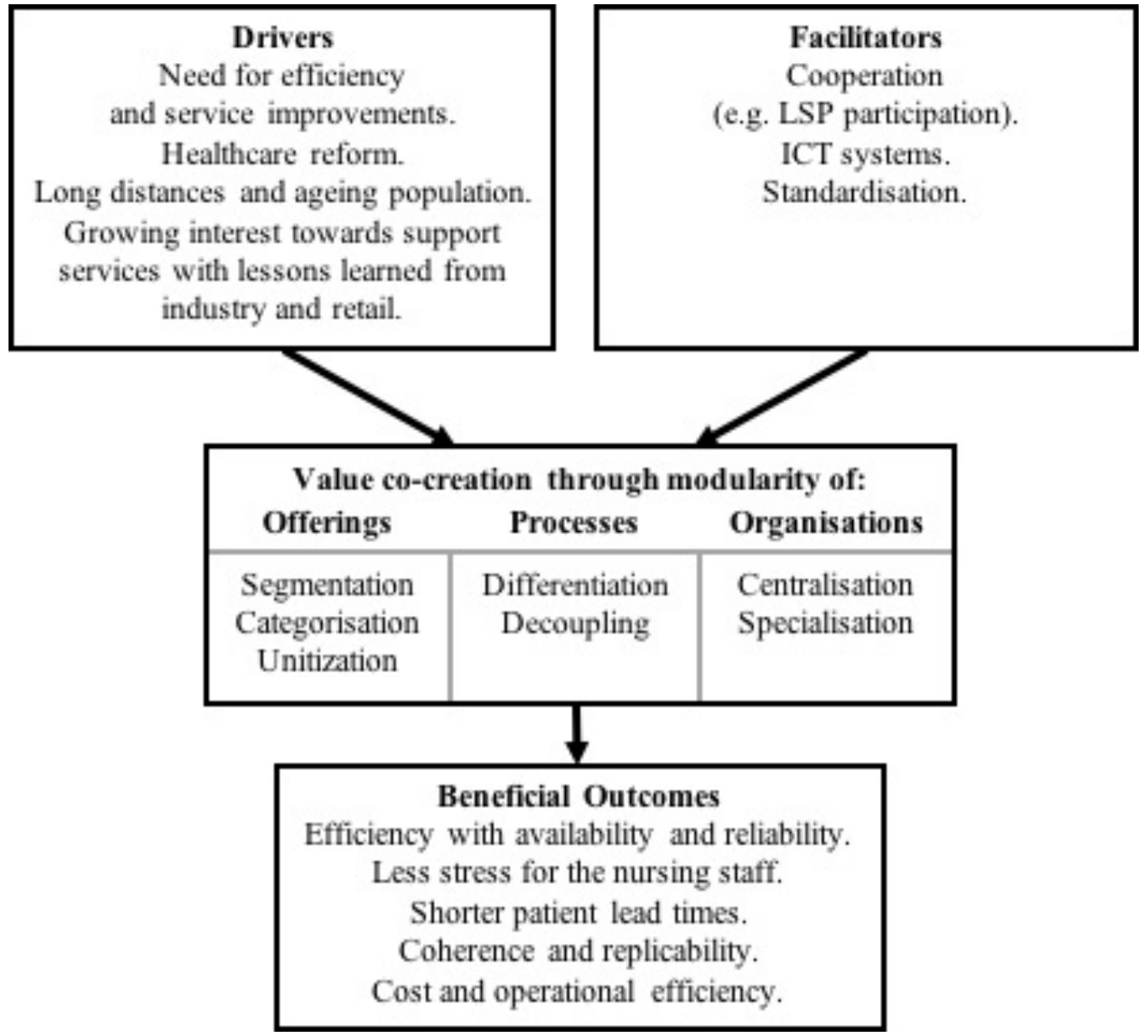

Figure 2. Antecedents, components and outcomes of value co-creation through modularity in healthcare material logistics. 
This study contributes to the evolving literature on service modularity, especially in the healthcare management context. Based on empirical case evidence, the study proposes constituent components to the three dimensions of modularity - service offerings, processes and organisations (Pekkarinen and Ulkuniemi, 2008). In addition, the paper clarifies through practical examples the link between modularity and value creation to achieve the desired outcomes. These empirically grounded observations introduce a cognitive frame for managing healthcare logistics services and new ingredients to the theory building around the service modularity concept.

From a managerial perspective, the findings suggest that modularisation clarifies the roles and responsibilities between the different actors in healthcare organisations. Apart from in-house service organisations, modularisation increases opportunities for considering external providers for support activities such as logistics. The modularisation process may involve obstacles, for instance when product assortments are standardised, but it also looks like attitudes may change as experiences grow.

Besides monetary benefits, modularity also provides various non-monetary values, such as growing opportunities for specialisation and the ability of nursing personnel to focus on actual patient work. Thus, modularising healthcare logistics services has potential social implications in developing healthcare processes and changing the usage of health services. On a wider scale, modularity is doing its share in helping healthcare systems reach their goals in terms of service quality and cost.

This study was conducted in an interdisciplinary research project in a largely exploratory manner. Multiple data collection methods were used to gain an understanding of the subject. Follow-up research is needed to refine and operationalise the key dimensions of service modularity and their link to the proposed components for managing in the rapidly developing field of healthcare logistics. For instance, an item-level analysis of different product categories in the regional healthcare units, together with their replenishment models, is needed to show the true potential of modularity in service offerings of the logistics support organisation. It is also of interest to study whether synergy in logistics could be achieved between the public organisations and the growing number of private companies that have entered the healthcare business. Besides Finland, this would also be an important topic in other sparsely populated regions, for instance in other Nordic countries, perhaps involving the possibilities for cross-border cooperation in logistics and other support operations.

This study contributes to the evolving literature on service modularity, especially in the healthcare management context. Based on empirical case evidence, the study proposes constituent components to the three dimensions of modularity-service offerings, processes and organisations (Pekkarinen and Ulkuniemi, 2008). In addition, the paper clarifies through practical examples the link between modularity and value creation to achieve the desired outcomes. These empirically grounded observations introduce a cognitive frame for managing healthcare logistics services and new ingredients to the theory-building around the service modularity concept.

From a managerial perspective, the findings suggest that modularisation clarifies the roles and responsibilities between the different actors in healthcare organisations. Apart from in-house service organisations, modularisation increases opportunities for considering external providers for support activities such as logistics. The modularisation process may involve obstacles, for instance when product assortments are standardised, but it also looks like attitudes may change as experiences grow.

Besides monetary benefits, modularity also provides various non-monetary values, such as growing opportunities for specialisation and the ability of nursing personnel to focus on actual patient work. Thus, modularising healthcare logistics services has potential social implications in developing healthcare processes and changing the usage 
of health services. On a wider scale, modularity is doing its share in helping healthcare systems reach their goals in terms of service quality and cost.

This study was conducted in an interdisciplinary research project in a largely exploratory manner. Multiple data collection methods were used to gain an understanding of the subject. Follow-up research is needed to refine and operationalise the key dimensions of service modularity and their link to the proposed components for managing in the rapidly developing field of healthcare logistics. For instance, an item-level analysis of different product categories in the regional healthcare units, together with their replenishment models, is needed to show the true potential of modularity in service offerings of the logistics support organisation. It is also of interest to study whether synergy in logistics could be achieved between the public organisations and the growing number of private companies that have entered the healthcare business. Besides Finland, this would also be an important topic in other sparsely populated regions, for instance in other Nordic countries, perhaps involving the possibilities for cross-border cooperation in logistics and other support operations.

\section{Acknowledgements}

This research is part of the project entitled "Effective, user-centred and scalable support service models in long-distance healthcare systems". The authors acknowledge the "Innovations in Social and Healthcare Services" programme of Tekes (now Business Finland) and other public and private organisations for funding this research. The authors express warm thanks to the representatives of the hospital and logistics service organisations for fruitful discussions that have significantly improved this paper. The authors are grateful to the project members, especially Minna Hautamäki and Petri Westerlund for their valuable work on the empirical part of this research. 


\section{References}

Aastrup, J. and Halldórsson, Á. (2008), "Epistemological role of case studies in logistics: a critical realist perspective", International journal of physical distribution \& logistics management, Vol. 38 No, 10, pp. 746-763.

Abdulsalam, Y., Gopalakrishnan, M., Maltz, A. and Schneller, E. (2015), "Health care matters: Supply chains in and of the health sector", Journal of Business Logistics, Vol. 36, pp 335-339.

Baldwin, C. Y. and Clark, K. B. (2000), Design rules: The power of modularity, Vol. 1. MIT press.

Bask, A., Lipponen, M., Rajahonka, M. and Tinnilä, M. (2010), "The concept of modularity: diffusion from manufacturing to service production”, Journal of Manufacturing Technology Management, Vol. 21 No. 3, pp. 355-375.

Beier, F. J. (1995), "The management of the supply chain for hospital pharmacies: a focus on inventory management practices", Journal of Business Logistics, Vol. 16 No 2, pp. 153.

Brax, S.A., Bask, A., Hsuan, J. and Voss, C. (2017), "Service modularity and architecture-an overview and research agenda", International Journal of Operations \& Production Management, Vol 37 No 6, pp. 686-702.

Broekhuis, M., Eissens Van der Laan, M. and Van Offenbeek, M. (2017), "What professionals consider when designing a modular service architecture", International Journal of Operations and Production Management, Vol. 37 No. 6, pp. 748-770.

Campagnolo, D. and Camuffo, A. (2010), "The concept of modularity in management studies: A literature review", International Journal of Management Reviews, Vol. 12 No 3, pp. 259-283.

Cardoen, B., Beliën, J. and Vanhoucke, M. (2015), "On the design of custom packs: grouping of medical disposable items for surgeries", International Journal of Production Research, Vol 53 No. 24, pp. 73437359.

Day, G. S. (1990), Market-driven strategy: Processes for creating value, New York: The Free Press.

de Blok, C., Meijboom, B., Luijkxc, K., Schols, J. and Schroeder, R. (2014), "Interfaces in service modularity: A typology developed in modular health care provision", Journal of Operations Management, Vol. 32 No. 4, pp. 175-189.

de Vries, J. and Huijsman R. (2011), "Supply chain management in health services: an overview", Supply Chain Management: An International Journal, Vol. 16 No. 3, pp. 159 - 165.

Feitzinger, E. and Lee, H.L. (1997), "Mass customization at Hewlett-Packard: The power of postponement", Harvard Business Review, Vol. 75 No. 1, pp. 116-121.

Frandsen, T. (2017)," Evolution of modularity literature: a 25-year bibliometric analysis", International Journal of Operations \& Production Management, Vol. 37 No. 6, pp. 703-747.

Fugate, B.S., Mentzer, J.T. and Stank, T.P. (2010), "Logistics performance: efficiency, effectiveness, and differentiation", Journal of Business Logistics, Vol. 31 No. 1, pp. 43-62.

Gammelgaard, B. (2004), "Schools in logistics research? A methodological framework for analysis of the discipline", International Journal of Physical Distribution \& Logistics Management, Vol. 34 No. 6, pp. 479-491.

Godsell, J., Diefenbach, T., Clemmow, C., Towill, D., and Christopher, M. (2011), ”Enabling supply chain segmentation through demand profiling”, International Journal of Physical Distribution \& Logistics Management, Vol. 41 No.3, pp. 296-314.

Grönroos, C. and Voima, P. (2013), "Critical service logic: making sense of value creation and co-creation", Journal of the Academy of Marketing Science, Vol. 41 No. 2, pp. 133-150.

Gualandris, J. and Kalchschmidt, M. (2013), "Product and process modularity: improving flexibility and reducing supplier failure risk", International Journal of Production Research, Vol. 51 No. 19, pp. 5757577.

Gärtner, C. and Schön, O. (2015), "Modularizing business models: between strategic flexibility and path dependence”, Journal of Strategy and Management, Vol. 9 No. 1, pp. 39-57.

Helfat, C. E., and Eisenhardt, K. M. (2004), "Inter-temporal economies of scope, organizational modularity, and the dynamics of diversification", Strategic Management Journal, Vol. 25 No. 13, pp 1217-1232.

Helkkula, A., Kelleher, C. and Pihlström, M. (2012), "Characterizing value as an experience: implications for service researchers and managers", Journal of Service Research, Vol. 12 No. 1, pp. 59-75. 
Janssen, M. and Joha, A. (2008), "Emerging shared service organizations and the service oriented enterprise: Critical management issues", Strategic Outsourcing: An International Journal, Vol. 1 No. 1, pp. 35-49.

Jarrett, G. P. (1998), "Logistics in the health care industry", International Journal of Physical Distribution \& Logistics Management, Vol. 28 No. 9/10, pp. 741-772.

Kaplan, R.S. and Porter M.E., (2011), "How to solve the cost crisis in health care", Harvard Business Review, Vol. 89 No. 9, pp. 46-52.

Ketokivi, M. and Choi, T. (2014), "Renaissance of case research as a scientific method", Journal of Operations Management, Vol. 32, pp. 232-240.

Kriegel, J., Jehle, F., Dieck, M. and Mallory, P. (2013), "Advanced services in hospital logistics in the German health service sector", Logistics Research, Vol. 6 No. 2-3, pp. 47-56.

Kumar, A., Ozdamar, L. and Ning Zhang, C. (2008), "Supply chain redesign in the healthcare industry of Singapore", Supply Chain Management: An International Journal, Vol. 13 No. 2, pp. 95-103.

Lambert, D.M., Cooper, M.C. and Pagh, J.D. (1998), "Supply chain management implementation issues and research opportunities", The International Journal of Logistics Management, Vol. 9 No. 2, pp. 120.

Lambert, D.M., Emmelhainz, M.A. and Gardner J.T. (1996), "Developing and implementing supply chain partnerships", The International Journal of Logistics Management, Vol. 7 No. 2, pp. 1-18.

Landry, S. and Philippe, R. (2004), "How logistics can service healthcare", Supply Chain Forum: An International Journal, Vol. 5 No. 2, pp. 24-30.

Lin, Y., Pekkarinen, S. and Ma, S. (2015), "Service-dominant logic for managing the logisticsmanufacturing interface: A case study", International Journal of Logistics Management, Vol. 26 No. 1, pp. $195-214$.

Macdonald, E., Wilson, H., Martinez, V. and Toossi, A. (2011), "Assessing value-in-use: A conceptual framework and exploratory study", Industrial Marketing Management, Vol. 40 No. 5, pp. 671-682.

MacDuffie, J. P. (2013). "Modularity-as-property, modularization-as-process, and 'modularity'-as-frame: Lessons from product architecture initiatives in the global automotive industry", Global Strategy Journal, Vol. 3 No. 1, pp. 8-40.

Menor, L.J. and Johnson, P.F. (2012), "Service operations management and service supply network triadic arrangements", in 4th World Conference Production \& Operations Management.

Metters, R. and Vargas, V. (2000), "A typology of de-coupling strategies in mixed services", Journal of Operations Management, Vol. 18 No 6, 663-682.

Mikkola, J.H. (2003), "Modularity, component outsourcing, and inter-firm learning", R\&D Management, Vol. 33 No. 4, pp. 439-454.

Möller, K.E. and Törrönen, P. (2003), "Business suppliers' value creation potential. A capability-based analysis", Industrial Marketing Management, Vol. 32 No. 2, pp. 109-118.

O'brien, J. (2015), Category management in purchasing: a strategic approach to maximize business profitability. London: Kogan Page.

Orton, J.D. (1997), "From inductive to iterative grounded theory: Zipping the gap between process theory and process data", Scandinavian Journal of Management, Vol. 13 No. 4, pp. 419-438.

Pekkarinen, S. and Ulkuniemi, P. (2008), "Modularity in developing business services by platform approach", The International Journal of Logistics Management, Vol. 19 No. 1, pp. 84-103.

Persson, G. (1995), "Logistics process redesign: some useful insights", The International Journal of Logistics Management, Vol. 6 No 1, pp. 13-26.

Piercy, N.F. and Morgan, M.A. (1997), "The impact of lean thinking and the lean enterprise on marketing: Threat or synergy?" Journal of Marketing Management, Vol. 13 No 7, pp. 679-693.

Rajahonka, M., Bask, A. and Lipponen, M. (2013), "Modularity and customisation in LSP's service strategies", International Journal of Services and Operations Management, Vol. 16 No. 2, pp. 174-204.

Rutenberg, D.P. (1971), "Design commonality to reduce multi-item inventory: Optimal depth of a product line", Operations Research, Vol. 19 No. 2, pp. 491-509.

Salvador, F. (2007), "Toward a Product System Modularity Construct: Literature Review and Reconceptualization", IEEE Transactions on Engineering Management, Vol. 54 No. 2, pp. 219.

Salvador, F., Rungtusanatham M. and Forza C. (2004), "Supply-chain configurations for mass customization", Production Planning \& Control, Vol. 15 No. 4, pp. 381-397. 
Sandoff, M. (2005), "Customization and standardization in hotels - a paradox or not?", International Journal of Contemporary Hospitality Management, Vol. 17 No 6, pp. 529-535.

Schilling, M.A. and Steensma, H.K. (2001), "The use of modular organizational forms: An industry-level analysis", Academy of Management Journal, Vol. 44 No. 6, pp. 1149-1168.

Silander, K., Torkki, P., Lillrank, P., Peltokorpi, A., Brax, S.A. and Kaila, M. (2017), "Modularizing specialized hospital services: constraining characteristics, enabling activities and outcomes", International Journal of Operations \& Production Management, Vol. 37 No 6.

Simchi-Levi, D. (2010), Operations Rules: Delivering Customer Value Through Flexible Operations. The Mit Press.

Simchi-Levi, D., Kaminsky, P. and Simchi-Levi, E. (2008), Designing and Managing the Supply Chain: Concepts, Strategies and Case Studies. Boston: McGraw-Hill.

Soffers, R., Meijboom, B., van Zaanen, J. and van der Feltz-Cornelis, C. (2014), "Modular health services: a single case study approach to the applicability of modularity to residential mental healthcare", $M M C$ Health Services Research, Vol. 14 No. 1, pp. 1-10.

Stewart, D.W. and Shamdasani, P.N. (2014), Focus groups: Theory and practice (Vol. 20). Sage publications.

Ulkuniemi, P. and Pekkarinen, S. (2011), "Creating value for the business service buyer through modularity", International Journal of Services and Operations Management, Vol. 8 No. 2, pp. 127141.

Vähätalo, M. and Kallio, T.J. (2015), "Organising health services through modularity", International Journal of Operations \& Production Management, Vol. 35 No. 6, pp. 925-945.

Volland, J., Fügener, A., Schoenfelder, J., and Brunner, J.O. (2017), "Material logistics in hospitals: a literature review", Omega, Vol 69, 82-101.

Voss, C.A. and Hsuan, J. (2009), "Service architecture and modularity", Decision Sciences, Vol. 40 No. 3 , pp. 541-569.

Woodruff, R.B. (1997), "Customer value: the next source for competitive advantage", Journal of the academy of marketing science, Vol. 25 No. 2, pp. 139-153.

Yin, R. (2013), Case Study Research. Design and Methods, $5^{\text {th }}$ ed., Thousand Oaks, CA. 